\title{
IN SEARCH OF THE BEST TECHNIQUE FOR VOCABULARY ACQUISITION
}

\section{Mohammad Mohseni-Far}

\begin{abstract}
The present study is intended to critically examine vocabulary learning/acquisition techniques within second/foreign language context. Accordingly, the purpose of this survey is to concentrate particularly on the variables connected with lexical knowledge and establish a fairly all-inclusive framework which comprises and expounds on the most significant strategies and relevant factors within the vocabulary acquisition context. At the outset, the study introduces four salient variables; learner, task and strategy serve as a general structure of inquiry (Flavell's cognitive model, 1992). Besides, the variable of context is introduced to enrich the examination process. The analysis specifically looks in depth at task-dependent strategies for this variable is much more substantial and yet in practice possesses more pedagogical implications. In lieu of seeking out superior strategies and techniques that bring about optimal outcomes, the investigator lays stress on the relative effectiveness of each individual strategy and technique. The organic idea of this exploration is that the most effectual and successful lexical development will occur in flexible and highly interactive syllabuses with a pedagogically well-reasoned balance between explicit and implicit activities.
\end{abstract}

Keywords: vocabulary learning/acquisition, lexical knowledge, lexical development, strategies and techniques, curriculum development

\section{Introduction}

Psychologists, linguists and language teachers have long been interested in vocabulary learning strategies. They have attempted to understand the role of the lexicon in language learning and communication. In particular, during the past fifteen years, the field of second language acquisition (SLA) has witnessed renewed attention to vocabulary learning and acquisition. There are many dimensions to 
vocabulary acquisition, as reflected in the multitude of different areas of research being conducted on the topic.

In general, one way to study the task of vocabulary learning/acquisition is through the distinction between knowing a word and using a word. In operational terms, knowing a word may be seen as a continuum ranging from blurry recognition of its spelling or auditory pattern to (semantically, syntactically, stylistically) correct and contextually appropriate productive use. Retrieval of a word from the mental lexicon for productive use requires a higher degree of accessibility or, in other words, a more solid integration in various networks than is needed for receptive use (Groot 2000: 76). In other words, the purpose of vocabulary learning should include both recalling words and the ability to apply them automatically in a wide range of language contexts when the need arises. Vocabulary learning strategies, therefore, have to incorporate strategies for recognizing and knowing as well as using words. On the other hand, Henriksen (1999) draws attention to the fact that the acquisition of word meaning actually involves two interrelated processes: item learning (adding to the lexical store by creating extensional links, i.e. form-meaning mappings) and system changing (re-ordering/changing the lexical store via network building). The tendency in L2 vocabulary acquisition research has been to neglect the latter and focus on the former.

Another way to view vocabulary learning is to take it as a process of interconnected sub-tasks. When learners first encounter a new word, they might guess its meaning and usage from accessible tokens. Some learners might resort to consulting a dictionary. Others might make notes in the margins, between lines, or in a separate vocabulary notebook. Some learners will take advantage of simple rote repetition to commit the word to memory. Some would even attempt to use the word enthusiastically in a real context. Each of these task stages demands metacognitive decision, choice, and deployment of cognitive strategies for vocabulary learning. And each technique a learner puts to use will determine to a large degree how and how well a new word is learned/acquired.

This survey aims to profile a digest of recent research on vocabulary acquisition and to pinpoint areas that need further investigation. To this end, the paper centers on one particular area in depth, namely, vocabulary learning strategies. In so doing, it attempts to synthesize the most important and recent findings of research into vocabulary learning and acquisition, and to outline each of the main areas of research on the topic.

\section{Critical survey}

\subsection{Preview}

Mastery of vocabulary is an essential component of SLA. Effective L2 vocabulary acquisition is particularly important for foreign language learners who frequently acquire impoverished lexicons despite years of formal study (Hunt, Beglar 2005: 1). Today's language teachers and researchers have realized the important role of vocabulary in different pedagogical tasks. There is no doubt that virtually all L2 learners and their teachers are well aware of the fact that learning a L2 involves the learning of large numbers of words (Avila, Sadoski 1996, Laufer, Hulstijn 2001), yet 
how to accomplish this task is often of considerable concern to them (Ott, Blake, Butler 1976: 37). How vocabulary is acquired and what the most efficient means are to promote effective acquisition are well established lines of enquiry in the field of SLA (De La Fuente 2002: 82).

The acquisition of a new lexical item is a complex process. Ellis, Tanaka and Yamazaki (1994: 457) argue that vocabulary acquisition involves discovering the frequency with which the item is used in speech and writing, its situational and functional uses, its syntactic behavior, its underlying form and the forms that can be derived from it, the network of associations between it and other items, its semantic features and, of course, the various meanings associated with the item. Due to this complexity, research on L2 vocabulary acquisition encompasses a number of different and diverse sub-areas. For example, how words are stored in the mental lexicon, automaticity of retrieval, the role of vocabulary in reading comprehension, the role of background knowledge, the implications of L2 vocabulary acquisition for L1 vocabulary research, how words are learned in context and other strategies for reading in L2 (Chun, Plass 1996: 184).

However significant lexical knowledge and vocabulary acquisition may be, the techniques and strategies recommended in this field remain challenging (Newton 2001: 30, Mohseni-Far 2006: 149). Although researchers and language teachers are becoming more and more convinced that vocabulary knowledge constitutes an essential part of competence in a L2, so far no comprehensive theories have been proposed that try to explain foreign language growth in terms of lexical development (Bogaards 2001: 321). In spite of the expansion in the amount of empirical research on vocabulary acquisition, consensus is lacking over issues such as the conceptualization of the process by which vocabulary acquisition occurs, the importance of context for acquiring vocabulary, and the extent to which learners build up specific strategies for vocabulary learning during their language acquisition.

In order to conduct the paper in a more systematic way, four prominent variables are taken into consideration; three from a cognitive model suggested by Flavell (1992), i.e., learner, task, strategy, as a general frame for the investigation as well as the variable of context. Initially, these four factors are introduced and defined, then in following chapters they are dealt with in more detail. Having taken these four variables into account, the paper also tries to shed significant light on major issues and controversies concerning each variable.

\subsection{Cognitive variables and context}

The four variables learner, task, context, and strategy are interconnected and work together to form the scaffold of learning/acquisition. The strategies a learner exercises and the effectiveness of these strategies very much depend on the learner him/herself (e.g., attitudes, motivation, prior knowledge, topic familiarity), the learning task at hand (e.g., type, complexity, difficulty, and generality), and the context or learning milieu (e.g., the learning culture, the influence of input and output opportunities). Therefore, an analysis of learning strategies will never be complete without identifying the learner, task and context configuration of the particular learning situation. Some strategies are more learner-dependent, some are more task-dependent, and others are more context-contingent. 
The variable learner needs to be discussed from different perspectives. The leaner brings to the language learning situation a wide spectrum of individual differences that will influence the learning rate and the ultimate learning result ( $\mathrm{Gu}$ 2003: 2). The most widely reported learner factors include gender, language attitude, intelligence, prior knowledge, motivation, self-concept/image, personality, and cognitive and learning style. Motivation, emotion, and socio-cultural factors may affect the way in which people process information (Laufer, Hulstijn 2001: 7). The learner-dependent factors noted above to a large extent define how a learner handles a task.

The conception of the learning task incorporates materials being learned (such as the genre of a piece of reading) as well as the end the learner is attempting to achieve by using these materials (such as remembering, comprehending, or using language). Task can be defined as an activity or action which is carried out as a result of processing or understanding language. Laufer and Hulstijn (2001: 17) refine the meaning of task in the field of vocabulary acquisition in particular as "an activity in which meaning is primary".

It is necessary to distinguish between two types of context. First, the learning context, which refers to the "learning environment and includes the teachers, the peers, the classroom climate or ethos, the family support, the social, cultural tradition of learning, the curriculum, and the availability of input and output opportunities" (Gu 2003: 2). Second, the language context, which refers to the textual or discoursal place in which a particular word or structure can be found. Great importance has been attached to the latter by researchers and accordingly it will be subjected to fairly extensive and detailed investigation within this study. In support of the significance of context, Lawson and Hogben (1996: 106) suggest that from a psychological as well as a linguistic point of view, underlying the first guideline would be the need for vocabulary to be learned in context. Activities and reading materials that present words in meaningful contexts may contribute to vocabulary gains and are valued highly by students (Zimmerman 1997: 136).

A learning strategy (technique) covers a series of activities and efforts a learner makes to facilitate the completion of a learning task. Vocabulary learning strategies are any set of operations, steps, plans, routines used by the learner which affect this process. A technique is initiated when the learner examines the task, the situation, and what is available in his/her own mind. The learner then goes on to select, deploy, monitor, and weigh up the effectiveness of this activity, and decides if s/he needs to revise the plan and action. Theorists now place considerable stress on the importance of foreign language students' developing autonomous learning strategies (Favretti, Silver, Tamburini, Gasser, quoted in Lawson, Hogben 1996: 106). Contextual guessing, skilful use of dictionaries, note-taking, paying attention to word formation and contextual encoding are some strategies normally applied by learners. Wenden (1987: 6) points out that language learning strategies have to consider different aspects of the language learning process. She identifies three areas in particular that language learning strategies refer to: (a) the actual behaviour of learners (what do learners do to learn an L2), (b) strategic knowledge (what learners know about the strategies they use), and (c) knowledge about aspects (other than strategies) of the L2 learning process, such as personal/motivational factors. These areas are summed up by Rubin (1987) as "what learners do to learn and do to regulate their [language] learning”. Language learning strategies are applicable to 
a wide variety of language learning tasks, ranging from rather discrete and isolated tasks such as vocabulary, pronunciation and grammar to integrative tasks like oral communication and reading comprehension.

\section{Vocabulary learning strategies: task-dependant perspective}

Vocabulary learning strategies constitute a subclass of language learning strategies which in turn are a subclass of learning strategies in general. Fewer studies can be found on learner-related vocabulary learning strategies. Most of the empirical investigations on vocabulary learning strategies in a second language have focused on different sub-tasks of vocabulary learning. The emphasis of this study is placed upon this variable as well.

\subsection{Inferring and vocabulary learning}

The premise underlying this line of research is the belief that the vast majority of words learned in the L1 result from extensive and manifold exposures rather than direct instruction, and therefore successful vocabulary learning in a L2 should proceed in the same way. A number of topics have been put forward in the literature: guessing leading to vocabulary learning, inference from context, exposures needed to learn a word, and incidental (implicit) vocabulary learning and intentional (explicit) learning. Each of these is dealt with critically below in the chapter 3.3.

One of the strategies most often discussed in the literature is guessing word meaning from the clues made available by the context. Factors that affect the likelihood of success in inferencing include a context rich enough to provide adequate clues to guess a word's meaning (Celce-Murcia 2001: 290). Put another way, the unknown word to be guessed has to have plenty of comprehensible supporting context (Nation, Meara 2002: 44). In order to discuss this issue from a pedagogical standpoint, it is better to use the technical alternative "inferring" meaning from the context instead of "guessing".

In a sense, inference from context (IFC) is the mirror image of incidental acquisition on the strategy side. Nation has championed IFC as the "undoubtedly most important vocabulary learning strategy" (1990: 130), and recommends IFC especially for low-frequency words as their rarity does not repay the learning effort. One difficulty in this area of research is that there is no standard characterization of what is intended by context. In its broadest sense, of course, context may be said to comprise all the perceived phenomena that accompany the processing of a given stimulus, including the physical surroundings in which learning take place (Prince 1996: 479). Using the meanings of words together within the whole meaning of the sentence is the deepest level of processing and ensures the best memory (Cook 1991: 36). Crucial to inferring meaning from context is the degree to which context unveils word meaning. This degree is restricted by the learner's own background knowledge and constraints in the text itself. Hence, both teachers and learners must be aware that context functions to restrict meaning as well as to reveal it. 
Some contexts do not provide a lot of information about a word, but others provide information that can take knowledge of the word forward. Lawson and Hogben (1996) found a lack of association between IFC and recall of word meaning, which they interpret as emphasizing the need to distinguish the use of IFC for the generation of new word meanings, and their acquisition for subsequent recall. Shu, Anderson and Zhang (1995: 79) suggest that significant learning from context is evident only when unfamiliar words appear repeatedly. When a context is rich enough, it will be sufficient to allow a learner to infer the full word meaning. On the other hand, if a context is too easily understood, then no vocabulary acquisition takes place. For example, at superior levels of proficiency, and when reading for comprehension - rather than to explicitly learn the meaning of unfamiliar words - the context may be easily understood without having to determine the meaning of every unfamiliar word (Pulido 2003: 241). Pulido (2004: 472) also states that words that may be easily guessed in the course of reading may not be better retained because of the lack of a need to allocate sufficient attention to the connection between the new word form and its meaning.

Aside from the richness of context, prior/background knowledge (topic familiarity) and the learner's vocabulary proficiency level are of great importance. There are many reports in the psychological and SLA literature that greater levels of background knowledge and expertise in a given subject matter result in the greater efficiency of attentional allocation during reading and enable richer analyses and textual interpretations, and, in turn, superior memory performance (Pulido 2003: 236). In simple terms, a learner is more successful at lexical inferencing when $\mathrm{s} /$ he is familiar with the topic. Since activation of appropriate knowledge structures stored in long-term memory is necessary to construct and integrate meaning successfully across discourse, it stands to reason that it will also have a strong bearing on the construction of meaning at the textual level. As a result, text recall is enhanced when learners possess and utilize the appropriate background knowledge.

The other significant issue is the learner's vocabulary proficiency level. The stronger vocabulary a learner has, the better $\mathrm{s} / \mathrm{he}$ is able to understand the text that s/he interacts with (Chin 1999: 1). In an experiment, Prince (1996: 481) comes to the conclusion that advanced learners will make more efficient use of context than weaker learners, both during the study phase and during recall. To conclude, although IFC obviously has an important role to play in the overall scheme of vocabulary learning strategies (74\% of Schmitt's (1997) intermediate level L2 learners of English used IFC, and 73\% found it helpful), it cannot solve all reading comprehension, let alone acquisition, problems, and it needs to be supplemented by other vocabulary learning strategies.

\subsection{Frequency}

Frequency refers to the degree of probability of encountering a word in speech or print. It is obvious that the frequency of occurrence of the unknown words in the text has a significant impact on the retention of word meaning. The main reason given is that the reappearance of a word will strengthen the form-meaning connection in the learner's mental lexicon. In a more technical experiment by Hulstijn, Hollander and Greidanus (1996: 327) support was found for the hypothesis that frequency of 
occurrence will foster incidental vocabulary learning more when advanced second L2 learners are given the meanings of unknown words through marginal glosses or when they look up meanings in a dictionary than when no external information concerning the meaning of unknown words is available.

It is a rather complicated task to mention the precise or relative number of words and accordingly exposures in a text required to learn a word. In addition, the number of exposures needed for mastery of a new word lies in many factors such as the salience of the word in the context, the richness of contextual clues, the learner's interest and his/her existing repertoire of vocabulary.

\subsection{Incidental (implicit) vs. intentional (explicit) vocabulary learning}

In implicit vocabulary learning learners are engaged in activities that do not focus attention on vocabulary. Incidental vocabulary learning is learning that occurs when the mind is focused elsewhere, such as on understanding a text or using language for communicative purposes (Celce-Murcia 2001: 289). Huckin and Coady (1999) point out that implicit learning cannot be totally incidental as at least some attention must be paid to the input by the learner. The implicit vocabulary learning hypothesis has its roots in Krashen's seminal Input Hypothesis (Krashen 1989), which maintains that the meanings of new words are acquired subconsciously as a result of repeated exposures in a range of contexts, where the conscious focus is not on form, but on the message.

The explicit vocabulary learning hypothesis holds that the employment of a range of vocabulary learning strategies can greatly facilitate and enhance vocabulary acquisition; in this view, learners are seen as active processors of information (Ellis 1995). From a pedagogically-oriented perspective, the goal of explicit teaching is "to lead the learner's attention", whereas the aim of an implicit focus on form is "to draw the learner's attention". Moreover, individual tasks can be located along an explicit or implicit continuum, and complex tasks may combine both explicit and implicit subtasks. From a cognitive psychological perspective, explicit learning can be contextualized as a conscious searching, building and testing of hypotheses and assimilating a rule following explicit instruction, whereas implicit learning is characterized by the automatic abstraction of the structural nature of the material arrived at from experience of instance (Hunt, Beglar 2005: 3).

The following appear to be essentials for successful incidental acquisition to occur (Schmitt and McCarthy 1997, Groot 2000):

- Adequate level of language proficiency (the ability to accurately decode the orthographic form of new words);

- A large L2 vocabulary (deducing the meaning of an unknown word requires a thorough understanding of the context, which in turn presupposes a large vocabulary);

- Strategic knowledge of the inferencing process;

- Context sufficiently rich in cues.

While definitions begin to clarify explicit and implicit learning, questions remain concerning what features of vocabulary and grammar are best learned explicitly or implicitly and how these processes occur. In addition to distinguishing between 
explicit and implicit instruction, it is also necessary to consider which is more effective for promoting the acquisition of vocabulary knowledge. In fact, there is evidence in recent studies of second language learners that a combined approach is superior to a single learning method. Most researchers have recognized that a well-structured vocabulary programme needs a balanced approach that includes explicit teaching together with activities providing appropriate contexts for incidental learning (Celce-Murcia 2001: 286). Hunt and Beglar (2005: 3) also highlight the point that the most efficient learning involves a carefully selected combination of both explicit and implicit instruction and learning.

Finally, it should be mentioned that the most important explicit lexical instruction and learning strategies include lexis (word lists), using dictionaries and inferring from context, while the implicit approach primarily and basically involves learners in meaning-focused reading. In the preceding sections, inferring from context was discussed. Now, the role of the dictionary and then of meaning-focused reading will be examined.

\subsubsection{The role of the dictionaries}

Researchers are interested in investigating the part that dictionaries play in the learning of second language vocabulary. The dispute over the kind of dictionaries to be used in the foreign language classroom, and what dictionaries, if at all, should be used has always been an on-going one amongst language instructors and lexicographers. Presently, there is a prevalent view that L2 teachers should discourage learners from consulting dictionaries because extensive dictionary use can lead to word-for-word reading (Chin 1999: 3).

Three types of dictionaries are available: bilingual, monolingual, and bilingualized, and these can be found in either paper or electronic form. Both bilingual and monolingual dictionaries have their unique strong points and weaknesses for developing vocabulary knowledge.

Apart from the short and easy-to-understand definitions found in bilingual dictionaries, their strengths are: they can improve the reading comprehension of lower proficiency L2 learners, they assist vocabulary learning at all levels of proficiency (Hunt, Beglar 2005: 12). On the other hand, bilingual dictionaries 1) encourage translation, 2) foster one-to-one precise correspondence at word level between two languages, and 3) fail to describe adequately the syntactic behaviour of words (Gu 2003: 8).

In contrast, monolingual learners' dictionaries can be used to build and elaborate learner's vocabulary knowledge, using up-to-date and reliable sentence examples drawn from corpus data that provide information about meaning, grammar and usage (Hunt, Beglar 2005: 12). The monolingual entry can generally provide more detailed and precise information about idiomatic usage, common collocations, connotations, and register (Laufer, Hadar 1997: 189).

Since a combination of the good features of both types of dictionaries is attainable, there is considerable interest in the new bilingualized compromise dictionaries. A bilingualized entry typically includes: L2 definitions, L2 sentence information or L1 synonyms of the headword. These hybrid and fused dictionaries essentially provide translations in addition to retaining the good features of monolingual 
dictionaries. Using bilingualized dictionaries is more efficient than using separate bilingual and monolingual dictionaries, and these dictionaries are more flexible because beginning and intermediate learners can rely on the L1 translation and advanced learners can concentrate more on the L2 part of the entry (Laufer, Hadar 1997, Gu 2003, Hunt, Beglar 2005).

The above types of dictionaries are also available in various electronic forms (software, pocket electronic and online dictionaries). It is obvious that electronic dictionaries (e-dictionaries) are easier and more convenient to use than printed dictionaries. They frequently permit the learners to search multiple sources (grammar, text usage as well as thesaurus), save and review words and definitions. Some e-dictionaries offer advanced searches, provide multimedia annotations, such as illustrations and video that assist in reading comprehension and vocabulary learning (Chun, Plass 1996: 185).

Regardless of the dictionary selected, learners need to learn how to use it effectively. In order to use a dictionary effectively, it is worth noting that more research is needed on what exactly learners do and how their dictionary strategies influence their learning results.

Research findings are inconclusive as regards the benefit of dictionary look-up for vocabulary acquisition/comprehension. The purpose of Hulstijn's (1993) study was to examine the connection between look-up behaviour and vocabulary knowledge on the one hand and inference ability on the other hand, taking into account the influence of task variables such as reading goal, word relevance and word inferability. The result was that learners did not look up all unfamiliar words, with look-up behaviour most strongly related to the perceived relevance of the word, but only modestly to readers' vocabulary knowledge. Interestingly, the ability to infer word meaning from context was not related to look-up behaviour at all, which suggests that a substantial proportion of good guessers may have been inclined to check their guesses subsequently. Finally, there seems to be no significant difference in lexical knowledge between 'maximalists' (subjects who looked up many words) and 'minimalists' (Hulstijn 1992, Chun and Plass 1996).

\subsubsection{Meaning-focused reading}

Reading is one of the most important ways that learners gain lexical knowledge incidentally. Recent developments in lexical semantics tell us a lot about vocabulary learning. Concentration on meaning-focused reading will result in incremental increases in vocabulary size, the elaboration of lexical knowledge and development of reading fluency. Zimmerman (1997: 123) believes that a considerable amount of word learning takes place incidentally through exposure to new words in meaningful contexts. Implicit learning through meaning-focused reading can occur incidentally as a result of learners' engaging in such activities as integrated task sets (a series of tasks requiring the use of multiple skills), narrow reading, rereading, timed and paced readings, intensive and extensive reading (Hunt, Beglar 2005: 15). Swanborn and Glopper (2002: 98) also examine how reading texts for different purposes affects amounts of incidental word learning and then come to the conclusion that only the meaning of unknown words that are relevant for the reading purpose will be derived and recalled. Although these activities deserve greater attention, the 
investigator intends to place emphasis upon extensive reading as the primary means for implicit learning for two reasons: its potentiality for triggering L2 learners and the fact that it can take advantage of the amount of meaningful input accessible to learners.

\subsubsection{Extensive reading}

In extensive reading, learners select and read large amounts of materials that appeal to them and are within their level of comprehension. The core of a meaning-focused input strand of a course is a well-organized, well-monitored, substantial extensive reading programme (Nation, Meara 2002: 40). Shu et al. (1995: 79) lay stress on the point that learning from context through extensive reading might be one of the important sources in L1 vocabulary growth. Intermediate and advanced L2 learners enlarge their vocabulary to a great extent through incidental learning during extensive reading (Hulstijn et al. 1996: 337).

For extensive reading to be efficient, learners must be frequently exposed to large amounts of comprehensible text. Since the knowledge gained from a single encounter with a lexical item is likely to be forgotten unless rapidly followed by another encounter, repeated contextualized exposures are necessary to consolidate and secure word meaning. Harmon (1999: 306) advocates the promotion of wide reading as an important vehicle for vocabulary development because learners gain words from context during reading. Teachers can promote consolidation through the use of post-reading activities in which learners first notice the target words by highlighting, underlining or circling them, and then process them by classifying, analyzing, or using the items productively (Hunt, Beglar 2005: 9).

\subsection{Glosses and note-taking}

Textual glosses have been used for a long time to facilitate L2 reading; other forms of glosses include pictorial (visual) and aural glosses, and various combinations thereof. In general, there exists a consensus among researchers that glosses facilitate reading comprehension and short-term vocabulary retention (Kost et al. 1999). As for textual glosses, there is a choice of language and form (single-choice or multiple-choice) glossing. Some studies have explored the effectiveness of the different options: Laufer and Shmueli (1997) found that glosses in L1 (Hebrew) led to better retention than L2 (English) glosses. Multiple-choice glossing, while encouraging deeper processing, suffers (in the printed form) from its failure to provide immediate feedback for learner errors. This problem can be attended to by using computers, however; Nagata (1999) found multiple-choice glossing with immediate feedback to be more effective than single-choice glossing.

After getting information about a lexical unit, learners may take notes, in the form of vocabulary notebooks, vocabulary cards, or simply notes in the margins or between the lines (marginal glosses). Note-taking is one of the basic strategies often recommended by researchers in the field of vocabulary learning. Vocabulary cards are invaluable in consolidating primary gains because of their ease of use and the number of communicative activities in which they can be used, as well as their 
potentiality for increasing learner's enthusiasm. In a comparative empirical study Hulstijn et al. (1996: 336) conclude that the effect of marginal glosses will be greater than that of dictionary use because learners often do not make use of the dictionary. However, they then refine their conclusion in such a way that when readers do use a dictionary, the incidence of incidental vocabulary learning will be as good as, or even better than, when they are provided with marginal glosses.

\subsection{Mnemonics: the role of memory}

Among various other strategies frequently studied in the literature, one that requires a considerable amount of treatment and deep processing is mnemonics. Since vocabulary learning is essentially a memory matter, mnemonics should play a part in foreign language vocabulary learning as well. Mediation strategies - involving the new L2 word in some form of meaningful association - come in two varieties, imagery mediation and semantic mediation, and are examples of deep strategies. Imagery mediation in its plainest sense involves visualizing a mental picture or image of the L2 word in question; the most interesting variant of imagery mediation, however, is the keyword method (KW). KW has been mainly positively evaluated in the literature and can boast some impressive evidence of superiority over other direct or mnemonic strategies (Gu, Johnson 1996).

In the KW, the foreign word is remembered by being linked to a keyword, a similar sounding native word (the acoustic link), through an interactive image that involves both the foreign word and the native word (the imagery link). Avila and Sadoski (1996: 380) define the keyword method in two stages. First, the L1 word is associated with a familiar concrete word (keyword) based on acoustic similarities. The next stage is the production of an imaginal link between the target word and the keyword.

Since in this method the linkages from the vocabulary to a meaningful definition are provided, they will produce enhanced associative recall of definitions. As a result, the mnemonics links, particularly the imagery keyword technique, enable learners to memorize vocabulary more effectively. One of the frequently quoted claims of mnemonics is that people remember better over long periods of time if they have utilized mnemonic aids because they have a way to "get back at the word again" (Ott et al. 1976: 45).

Irrespective of the advantages of this method, there exist some limitations:

1. As the keyword is merely an approximation of the L2 form, 'proper' learning of correct L2 phonology and orthography is unnecessarily delayed (although Hulstijn (1997) points out that there are no theoretical reasons to assume KW plays an inhibiting role).

2. It depends on the nature of the words (KW can only be used for concrete nouns, rarely for abstract ones).

3. The mnemonic approach to vocabulary development emphasizes an unchanging one-to-one relationship between form and meaning. However, a key view in the applied linguist's conception of vocabulary is manifold meanings and multiple dimensions of meanings (referential, syntactic, pragmatic, 
emotional, functional, literary, etc.). Especially in the case of polysemous words, it only helps establish one of the necessary meaning links.

4. Mnemonic devices are much less effective in productive vocabulary learning than in learning to comprehend the L2 because imagery association in the keyword technique allows retrieval of a keyword which is merely an approximation to the L2 form ( $\mathrm{Gu} 2003: 15)$.

Although the applications of KW (and other mnemonic techniques, for that matter) are limited, its efficiency and value have been sufficiently proven. It is perhaps best seen as a helpful addition and complementary strategy, but not a substitute, for other vocabulary learning strategies.

\subsection{Word-formation: focusing on form}

Knowledge of lexical roots (etymological information and morphological origins) can assist in vocabulary development in that it helps learners predict or guess what a word means, elucidate why a word is spelt the way it is, and remember the word by knowing how its current meaning develops from its morphological roots. Learners should learn to identify morphemes which recur in a number of words and which can help them to identify at least part of the meaning, thus assisting them in guessing from context the meaning of apparently new items (Rivers 1981: 465). Contextual information and word morphology (e.g., word roots, affixes, and inflectional suffixes) are two major sources that readers use to interpret novel words (Mori 2003: 404).

Although most words can be decomposed into root words, prefixes, and suffixes, the degree to which these components specify the meaning of the whole varies widely. Shu et al. (1995: 80) introduce two major categories of words. First, the meaning of some words can easily be determined on the basis of the constituent morphemes or 'word parts' with little or no help from context (morphologically transparent words). Second, at the other extreme are words for which the components contribute almost nothing to the meaning (morphologically opaque words). In general, most words fall in between; although their meanings cannot be derived solely on the basis of word parts, their meanings are likely to be clear when they appear in even a moderately helpful context.

In this regard, two studies by Bogaards (2001: 321) underscore the importance of knowledge of form - but not of previously learned meaning - for the learning of new meanings for familiar forms. Then, based on his first experiment, he concludes that totally new single-word units are harder to learn and retain than multiword units of the same meaning but with a form that is made up of familiar words. In another technical study on the effects of semantic and structural elaboration on L2 lexical acquisition, Barcrof (2002: 323) provides evidence that increased semantic elaboration (evaluation of an item with regard to its meaning) can inhibit one's ability to encode the formal [phonemic/graphemic] properties of new words. Furtermore, in an interesting experiment Nagy, McClure and Mir (1997: 431) state that first language syntactic knowledge influences guesses about the meanings of unfamiliar words in a second language context. This effect is found among bilinguals who have experienced a variety of amounts and types of exposure to English. 
A learner needs three skills in order to make use of affixation: breaking a new word into parts so that the affixes and roots are revealed; knowing the meaning of the parts; and being able to connect the meaning of the parts with the meaning of the word. Put another way, to make use of word parts, the learner needs to know the most useful word parts of English (20 or so high-frequency prefixes and suffixes are enough initially), needs to be able to recognize them in their various forms when they occur in words and needs to be able to relate the meanings of the parts to the meaning or definition (Nation, Meara 2002: 46).

\section{Vocabulary learning strategies: learner-dependant view}

From guessing at the first encounter, to possible dictionary use and note taking, to memorizing, encoding, and contextual activation, vocabulary acquisition is a dynamic process involving metacognitive choices and cognitive implementation of a whole spectrum of strategies. Whether and how a learner evaluates the task requirement and whether and how a cognitive strategy is utilized are often dependent more on the learner than on the task.

Researchers in the vocabulary learning strategy area have attempted to identify the ways in which "good" and "poor" learners approach lexical learning. Good learners are more aware of what they can learn about new words, pay more attention to collocation and spelling, and are more conscious of contextual learning. In contrast, poor learners are generally characterized by their apparent passivity in learning. Swanborn and Glopper (2002: 99) suggest that poor learners are not as adept as good learners at adjusting their reading strategies to fit the reading purpose and accordingly learning more affectively from context. In other words, good learners are good comprehenders and learners who are better skilled at handling vocabulary acquisition tasks. In a similar study, Pulido (2003: 239) states that strong learners tend to have more efficient decoding skills and larger sight vocabularies than weak learners. So these outcomes in reading performance can be explained by individual differences and strategies applied in these areas. Gu and Johnson (1996: 668) also studied 850 university English as a foreign language students in China, and tried to establish how different vocabulary strategies were related to language learning outcomes. Both Pearson's correlation and multiple regression analyses revealed that self-initiation, selective attention, and deliberate activation of newly learned words consistently predicted both vocabulary size and general proficiency. Other predictors of success included contextual learning, dictionary, and note-taking strategies.

\section{Discussion}

The factors and variables involved in vocabulary acquisition were critically discussed and analyzed in a rather comprehensive review of the relevant literature. The crucial notion developed here is that in lieu of seeking the best strategy that creates the best results, the relative efficiency of each individual strategy should be appreciated. In addition, the organic notion underlying this study is that the most effective and efficient lexical development will occur in multifaceted curriculums 
that attain a pedagogically sound equilibrium between explicit and implicit activities for L2 learners at all levels of their development.

The following points outline the most important implications of the issues covered here.

1. The focus of research in the linguistics tradition regarding vocabulary acquisition has largely centered on vocabulary learning (what is learned/to be learned; product-oriented view) rather than acquisition (how is vocabulary learned, process-oriented perspective) (Crow 1986, Meara 1980).

2. From a psychological standpoint, memory strategies have received the major share of attention in vocabulary acquisition, probably for the reason that this learning/acquisition process has largely been taken as a memory problem.

3. Much of the stress on incidental vocabulary learning has zeroed in on how helpful incidental learning is and how much can be learned incidentally, often ignoring the fact that a lot can be learned intentionally and by design during reading with the help of strategies (e.g., inferring from context, dictionary use, note-taking, as well as intentional repetition).

4. Research on vocabulary learning strategies does indicate a tendency for good learners to be more active than poor ones, but the field would benefit from a clearer focus on precisely how learners learn lexical units and how their strategies are related to acquisition outcomes (Schmitt 2000).

Research efforts have largely been directed towards discovering and supporting the best strategy for vocabulary retention. In reality, learners tend to utilize a variety of strategies in combination. Therefore, as highlighted in this paper, it seems highly preferable to seek to design a multifaceted framework with a pedagogically sound equilibrium that takes advantage of the positive and appropriate strengths of each strategy in a due and sensible time and at relevant level.

\section{Conclusion}

The main purpose of this survey was to review the effects of learning strategies on L2 vocabulary acquisition during recent years. Vocabulary acquisition can be best conceived as a process in which L2 learners negotiate word meaning from a text level to a word level. This shift is necessary so that the learner can form a mental connection between the word form and his/her meaning premise (Mohseni-Far 2006: 162).

Word knowledge has linguistic, psycholinguistic, and sociolinguistic aspects. Lexical competence is far more than the ability to define a given number of words; it entails knowing a great deal about each word, including information about its general frequency of use, the syntactic and situational limitations on its use, its generilizability, its collocational probabilities, its core form, its derived forms, and its semantic features. The process by which learners acquire this information appears to take place gradually over a long period of time and is very complex and difficult to investigate. In conclusion, a lot of work has been done to find overall patterns of strategy use. However, the choice, use, and effectiveness of vocabulary learning strategies very much depend on the task (e.g., breadth vs. depth), the learner (e.g., cognitive and cultural styles of learning, motivation), and the context. Future 
research, therefore, needs a more technical and closer approach that takes all the aforementioned features into account.

In operational terms, word knowledge includes the ability to recall meaning, infer meaning, comprehend a text, and communicate orally. No single approach can address all of these skills; when learners receive input about vocabulary only from reading or only from the use of lists, drills, or skill-building activities, they have not addressed the range of skills needed for word use. An effective approach to word learning should be multifaceted and comprehensive in what they require of the learner and rich in what they reveal about the target words. In a nutshell, the overall presumption must be that there is no simple answer to the key question of what the most efficient method/strategy of L2 word learning/acquisition is/should be. It depends very much on variables like degree of L1-L2 equivalence of the words to be learned, the intensity (both qualitative and quantitative) of processing, the age and cognitive level of the learner, the quantity and quality of rehearsal practice and variables discussed through this research. As a result, more experimentation systematically and analytically controlling these variables is required to collect data that will provide more insight into their relative importance and efficiency. Out of the meticulous examination of obtained results, a flexible, multi-purpose and eclectic skeleton and curriculum needs to be designed and developed so as to take best advantage of the strong points and effective potential of each strategy at its due time of utilization and which best fits with the existing overall characteristics of the pertinent task, context and learner. Therefore, a successful cognitive task performance (i.e. vocabulary acquisition) will be achieved within such a flexible, multiple-purpose and highly interactive framework.

\section{References}

Avila, E.; Sadoski, M. 1996. Exploring new applications of the keyword method to acquire English vocabulary. - Language Learning 46, 379-395.

Barcrof, J. 2002. Semantic and structural elaboration in L2 lexical acquisition. - Language Learning 52, 323-363.

Bogaards, P. 2001. Lexical units and the learning of foreign language vocabulary. - Studies in Second Language Acquisition 23, 321-343.

Celce-Murcia, M. 2001. Teaching English as a Second or Foreign Language. USA: Heinle \& Heinle.

Chin, C. 1999. The effects of three learning strategies on EFL vocabulary acquisition. - The Korea TESOL Journal 2, 1-29.

Chun, D. M.; Plass, J. L. 1996. Effects of multimedia annotations on vocabulary acquisition. The Modern Language Journal 80, 183-212.

Cook, V. 1991. Second Language Learning and Language Teaching. London: Edward Arnold.

Crow, J. T. 1986. Receptive vocabulary acquisition for reading comprehension. - The Modern Language Journal 70, 242-250.

De la Fuente, M. J. 2002. Negotiation and oral acquisition of L2 vocabulary. - Studies in Second Language Acquisition 24, 81-112.

Ellis, N. C. 1995. The psychology of foreign language vocabulary acquisition: Implications for CALL. - Computer Assisted Language Learning 8, 103-128.

Ellis, R.; Tanaka, Y.; Yamazaki, A. 1994. Classroom interaction, comprehension, and the acquisition of L2 word meanings. - Language Learning 44, 449-491. 
Flavell, J. H. 1992. Metacognition and cognitive monitoring. - T. O. Nelson (ed.). Metacognitive: Core Readings. Boston: Allyn and Bacon, 3-8.

Groot, P. J. M. 200o. Computer assisted second language vocabulary acquisition. - Language Learning \& Technology 4, 60-81.

Gu, Y. 2003. Vocabulary learning in a second language. - TESL-EJ 7, 1-26.

$\mathrm{Gu}, \mathrm{Y}$; Johnson, R. K. 1996. Vocabulary learning strategies and language learning outcomes. - Language Learning 46, 643-679.

Harmon, J. M. 1999. Initial encounters with unfamiliar words in independent reading. R.T.E. 33, 304-338.

Henriksen, B. 1999. Three dimensions of vocabulary development. - Studies in Second Language Acquisition 21, 303-317.

Huckin, T.; Coady, J. 1999. Incidental vocabulary acquisition in a second language: A review. Studies in Second Language Acquisition 21, 181-193.

Hulstijn, J. H. 1992. Retention of inferred and given word meanings: experiments in incidental vocabulary learning. - P. Arnaud, H. Béjoint (eds). Vocabulary and Applied Linguistics. London: Macmillan, 113-125.

Hulstijn, J. H. 1993. When do foreign-language readers look up the meaning of unfamiliar words? The influence of task and learner variables. - The Modern Language Journal 77, 139-147.

Hulstijn, J.H. 1997. Mnemonic methods in foreign language vocabulary learning: theoretical considerations and pedagogical implications. - J. Coady, T. Huckin (eds). Second Language Vocabulary Acquisition. Cambridge: Cambridge University Press, 203224.

Hulstijn, J. H.; Hollander, M.; Greidanus, T. 1996. Incidental vocabulary learning by advanced foreign language students: the influence of marginal glosses, dictionary use, and reoccurrence of unknown words. - The Modern Language Journal 80, 327-339.

Hunt, A.; Beglar, D. 2005. A framework for developing EFL reading vocabulary. - Reading in a Foreign Language 17, 1-31.

Kost, C. R.; Foss, P.; Lenzini, J. J. 1999. Textual and pictorial glosses: effectiveness on incidental vocabulary growth when reading in a foreign language. - Foreign Language Annals 32, 89-97.

Krashen, S. D. 1989. We acquire vocabulary and spelling by reading: additional evidence for the input hypothesis. - The Modern Language Journal 73, 440-464.

Laufer, B.; Hadar, L. 1997. Assessing the effectiveness of monolingual, bilingual, and "bilingualized" dictionaries in the comprehension and production of new words. - The Modern Language Journal 81, 189-196.

Laufer, B.; Hulstijn, J. 2001. Incidental vocabulary acquisition in a second language: the construct of task-induced involvement. - Applied Linguistics 22, 1-26.

Laufer, B.; Shmueli, K. 1997. Memorizing new words: Does teaching have anything to do with it? - RELC Journal 28, 89-108.

Lawson, M. J.; Hogben, D. 1996. The vocabulary learning strategies of foreign language students. - Language Learning 46, 101-135.

Meara, P. 1980. Vocabulary acquisition: a neglected aspect of language learning. - Language Teaching and Linguistics Abstracts 13, 221-246.

Mori, Y. 2003. The roles of context and word morphology in learning new Kanji words. - The Modern Language Journal 87, 404-420.

Mohseni-Far, M. 2006. Techniques utilized for vocabulary acquisition. - Language Forum $32,147-165$.

Nagy, W.; McClure, E. F.; Mir, M. 1997. Linguistic transfer and the use of context by SpanishEnglish bilinguals. - Applied Psycholinguistics 18, 431-452.

Nation, I. S. P. 1990. Teaching and Learning Vocabulary. Boston, MA: Heinle \& Heinle. 
Nation, P.; Meara, P. 2002. Vocabulary. - N. Schmitt (ed.). An Introduction to Applied Linguistics. London: Arnold, 35-54.

Nagata, N. 1999. The effectiveness of computer-assisted inteactive glosses. - Foreign Language Annals 32, 469-479.

Newton, J. 2001. Options for vocabulary learning through communication tasks. - ELT 55, $30-37$.

Ott, C. E.; Blake, R. S.; Butler, D. C. 1976. Implications of mental elaboration for the acquisition of foreign language vocabulary. - IRAL, XIV, 37-48.

Prince, P. 1996. Second language vocabulary learning: the role of context versus translations as a function of proficiency. - The Modern Language Journal 80, 478-493.

Pulido, D. 2003. Modeling the role of second language proficiency and topic familiarity in second language incidental vocabulary acquisition through reading. - Language Learning 53, 233-284.

Pulido, D. 2004. The relationship between text comprehension and second language incidental vocabulary acquisition: a matter of topic familiarity. - Language Learning 54, 469-523.

Rivers, W. M. 1981. Teaching Foreign-Language Skills. Chicago: The University of Chicago Press.

Rubin, J. 1987. Learner strategies: theoretical assumptions, research history and typology. A.Wenden, J. Rubin (eds). Learner Strategies in Language Learning. New York: Prentice Hall, 15-30.

Schmitt, N. 1997. Vocabulary learning strategies. - N. Schmitt, M. McCarthy (eds). Vocabulary: Description, Acquisition and Pedagogy. Cambridge : Cambridge University Press, 199-227.

Schmitt, N. 200o. Vocabulary in Language Teaching. Cambridge: Cambridge University Press.

Shu, H.; Anderson, R. C.; Zhang, H. 1995. Incidental learning of word meanings while reading: a Chinese and American cross-cultural study. - Reading Research Quarterly 30, 79-95.

Swanborn, M. S. L.; Glopper, K. D. 2002. Impact of reading purpose on incidental word learning from context. - Language Learning 52, 95-117.

Wenden, A. 1987. Conceptual background and utility. - A. Wenden, J. Rubin (eds). Learner Strategies in Language Learning. New York: Prentice Hall, 3-13.

Zimmerman, C. B. 1997. Do reading and interactive vocabulary instruction make a difference? an empirical study. - TESOL Quarterly 31, 121-140.

Mohammad Mohseni-Far (State University of Shahid Chamran, Ahwaz, Iran) is currently M.A. student majoring in TEFL/Applied Linguistics. He is the member of Iranian National Foundation of Elite and also Young Researchers Club (YRC), Islamic Azad University, Ahwaz-Iran. His main areas of interest: English for Specific Purposes (ESP), psycholinguistics, systemic functional linguistics (SFL), vocabulary acquisition, syllabus design, discourse analysis, theories of second language learning and teaching.

Mmb_m2005@yahoo.com

Mohammad Mohseni-Far, M.A.

Department of English,

Faculty of Humanities \& Letters,

Shahid Chamran University,

Ahwaz, Iran 


\section{PARIMAT SÕNAVARA OMANDAMISE MEETODIT OTSIMAS}

\section{Mohammad Mohseni-Far}

Shahid Chamrani Riiklik Ülikool, Ahwaz, Iraan

Käesolev kriitiline analüüs on suunatud sõnavara õppimise ja omandamise meetoditele teise või võõrkeele kontekstis. Lähtudes sõnavara tundmisega seotud muutujatest püütakse luua võimalikult kõikehõlmav raamistik mahutamaks sõnavara omandamise tähtsaimaid strateegiaid ja tegureid. Neli olulist muutujat on õppija, ülesanne ja strateegia (need moodustavad uurimuse põhistruktuuri, vt. Flavelli kognitiivne mudel) ning kontekst. Tähelepanu keskmes on ülesandekesksed strateegiad, kuna ülesanne on oluliselt sisukam muutuja, samas sõltub see õpetajast enam kui muud. Püüdmatagi esile tõsta parimaid strateegiaid ja meetodeid optimaalse tulemuse saavutamiseks, rõhutatakse iga üksiku strateegia ja meetodi suhtelist efektiivsust. Eelnevast järeldub loomulikult, et edukaim sõnavara areng toimub paindlikus ning võimalikult interaktiivses õpikeskkonnas, kus valitseb pedagoogiliselt hästi põhjendatud tasakaal eksplitsiitsete ja implitsiitsete opitoimingute vahel.

Märksõnad: sõnavara õppimine ja omandamine, sõnavara tundmine, sõnavara arendamine, strateegiad ja meetodid, õppekava arendamine 